\title{
No evidence for association between SLC11A1 and visceral leishmaniasis in India
}

\author{
Sanjana Mehrotra ${ }^{1,2}$, Joyce Oommen², Anshuman Mishra', Medhavi Sudharshan ${ }^{1}$, Puja Tiwary ${ }^{1}$, Sarra E Jamieson², \\ Michaela Fakiola ${ }^{2,3}$, Deepa Selvi Rani ${ }^{4}$, Kumarasamy Thangaraj ${ }^{4}$, Madhukar Rai ${ }^{1}$, Shyam Sundar ${ }^{1 \dagger}$ and \\ Jenefer M Blackwell ${ }^{2,3^{*}+}$
}

\begin{abstract}
Background: SLC11A1 has pleiotropic effects on macrophage function and remains a strong candidate for infectious disease susceptibility. 5' and/or 3' polymorphisms have been associated with tuberculosis, leprosy, and visceral leishmaniasis (VL). Most studies undertaken to date were under-powered, and none has been replicated within a population. Association with tuberculosis has replicated variably across populations. Here we investigate SLC11A1 and VL in India.

Methods: Nine polymorphisms (rs34448891, rs7573065, rs2276631, rs3731865, rs17221959, rs2279015, rs17235409, rs17235416, rs17229009) that tag linkage disequilibrium blocks across SLC11A1 were genotyped in primary familybased (313 cases; 176 families) and replication (941 cases; 992 controls) samples. Family- and population-based analyses were performed to look for association between SLC11A1 variants and VL. Quantitative RT/PCR was used to compare SLC11A1 expression in mRNA from paired splenic aspirates taken before and after treatment from 24 $V L$ patients carrying different genotypes at the functional promoter $\mathrm{GT}_{\mathrm{n}}$ polymorphism (rs34448891).
\end{abstract}

Results: No associations were observed between VL and polymorphisms at SLC11A1 that were either robust to correction for multiple testing or replicated across primary and replication samples. No differences in expression of SLC11A1 were observed when comparing pre- and post-treatment samples, or between individuals carrying different genotypes at the $\mathrm{GT}_{\mathrm{n}}$ repeat.

Conclusions: This is the first well-powered study of SLC11A1 as a candidate for VL, which we conclude does not have a major role in regulating VL susceptibility in India.

Keywords: SLC11A1, visceral leishmaniasis, genetic susceptibility

\section{Background}

Visceral leishmaniasis (VL) is a debilitating vector borne disease caused by parasites of the Leishmania donovani complex. Prevalence is high in Bihar State in India, indicating a need to understand more about disease pathogenesis to facilitate disease control. Population based epidemiological surveys suggest that $80-90 \%$ of individuals infected with $L$. donovani show no clinical symptoms $[1,2]$. Familial clustering, and the range of clinical outcomes from asymptomatic to fatal disease within and

\footnotetext{
* Correspondence: jmb37@cam.ac.uk

† Contributed equally

${ }^{2}$ Telethon Institute for Child Health Research, Centre for Child Health Research, The University of Western Australia, Subiaco, Western Australia, Australia

Full list of author information is available at the end of the article
}

between ethnic groups sharing similar risk factors in Brazil [3,4] and Sudan [5,6], support a contribution of host genotype to susceptibility. Candidate gene and genome-wide linkage studies have highlighted a number of genes/gene regions contributing to disease susceptibility (reviewed [7]). However, replication between study sites has not been observed possibly due to small samples size and limited statistical power.

Amongst the genes studied to date, the most compelling candidate for VL susceptibility is SLC11A1 (formerly NRAMP1). SLC11A1 encodes solute carrier family 11a member 1, a transporter that regulates divalent cation homeostasis in macrophages and has many pleiotropic effects on macrophage activation (reviewed $[8,9]$ ). The gene was first identified for its role in controlling 
Leishmania donovani (gene designation Lsh), Salmonella typhimurium (Ity) and Mycobacterium bovis (Bcg) infections in mice $[8,9]$. The positionally cloned [10] candidate for these 3 genes was designated as the natural resistance associated macrophage protein 1 (Nramp1) for a period before its specific function as a transporter was confirmed [11]. In mice, susceptibility to infection is associated with a coding region mutation in transmembrane domain 4 of Slc11a1 [10]. In humans, no functional coding region variants have been identified [12], but common alleles 2 [T $\left.(\mathrm{GT})_{5} \mathrm{AC}(\mathrm{GT})_{5} \mathrm{AC}(\mathrm{GT})_{10}\right]$ and $3\left[\mathrm{~T}(\mathrm{GT})_{5} \mathrm{AC}(\mathrm{GT})_{5} \mathrm{AC}(\mathrm{GT})\right.$ 9] of a functional [13] Z-DNA forming $\mathrm{GT}_{\mathrm{n}}$ repeat (rs34448891) in the promoter region have been associated with disease risk, or protection from, a number of autoimmune and infectious diseases (reviewed $[8,14]$ ). Amongst these associations, a common theme was risk of autoimmune disease with allele 3 which drives higher SLC11A1 expression and pro-inflammatory cytokine production by macrophages, while the lower expressing allele 2 was associated with anti-inflammatory cytokines and infectious disease susceptibility, including tuberculosis [15]. In contrast, in Sudan the proinflammatory $\mathrm{GT}_{\mathrm{n}}$ repeat allele 3 is on a risk haplotype for VL caused by $L$. donovani that includes variants at single nucleotide polymorphisms (SNPs) designated $274 \mathrm{C} / \mathrm{T}$ in exon 3 (rs2276631) and $469+14 \mathrm{G} / \mathrm{C}$ in intron 4 (rs3731865) in the 5 ' region of the gene [12]. This was interpreted in relation to VL pathology which is associated with a strong pro-inflammatory tumour necrosis factor alpha response [16]. In some populations infectious disease association (listed in additional on-line tables in reference [17]) has been with 3' variants at SLC11A1 rather than, or in addition to, the $5^{\prime}$ polymorphic loci, including two insertion/deletion (IN/DEL) polymorphisms TGTG/- (rs17235416) and CAAA/- (rs17229009) in the 3'UTR. The latter are potentially regulatory polymorphisms, although this has not been demonstrated experimentally. Here we report on well-powered two-stage primary family-based, followed by a replication population-based, genetic association study that fails to support either a role for polymorphism at SLC11A1 in determining susceptibility to VL caused by $L$. donovani in India, or for the $G_{\mathrm{n}}$ repeat polymorphism in determining mRNA expression levels of SLC11A1 in splenic aspirates from VL patients before or after chemotherapy.

\section{Methods}

The study was conducted in the district of Muzaffarpur in Bihar State, India, where VL is highly endemic. VL cases and family members or controls were from villages located within a radius of $\sim 100 \mathrm{~km}$ from the city of Muzaffarpur covering the districts of Muzaffarpur, Vaishali, Samastipur, Saran, Sheohar, East Champaran and Sitamarhi. Initially, families with at least two siblings affected with clinical VL were ascertained from medical records held in the Kala-
Azar Medical Research Centre (KAMRC) in Muzaffarpur, India [18]. This was later extended to collection of singleton cases plus parent (trios) (see Table 1A). The replication study comprised 958 unrelated cases and 1015 unrelated controls. The controls had no history of VL, or a family history of VL among first-, second- or thirddegree relatives. Patients and controls were matched for self-reported age, sex, religion, caste and geographic district of recruitment (see Table 1B). Diagnosis of VL was based on presence of typical clinical features of VL i.e. fever with rigors and chills, splenomegaly, weight loss and pancytopenia followed by demonstration of parasites by parasitological methods (light microscopy, in vitro culture) using splenic aspirates [19]. Additional VL cases identified in the field were confirmed on the basis of proof of medical records of diagnosis and treatment issued from one of the local health clinics or private practice, and

Table 1 Baseline characteristics of (A) families for the primary sample of Indian multicase VL families, and (B) the Indian case-control cohorts

\begin{tabular}{|c|c|}
\hline (A) Family Structure & Number* \\
\hline $\mathrm{N}^{\circ}$ families & 137 \\
\hline $\mathrm{N}^{\circ}$ nuclear families & 176 \\
\hline Nuclear families with 1 affected sib & 63 \\
\hline Nuclear families with 2 affected sibs & 95 \\
\hline Nuclear families with 3 affected sibs & 14 \\
\hline Nuclear families with 4 affected sibs & 2 \\
\hline Nuclear families with 5 affected sibs & 2 \\
\hline $\mathrm{N}^{\circ}$ affected offspring & 313 \\
\hline $\mathrm{N}^{\circ}$ affected parents & 63 \\
\hline Total $N^{\circ}$ affected individuals & 394 \\
\hline Total $\mathrm{N}^{\circ}$ individuals & 836 \\
\hline (B) Case-Control Sample & Number \\
\hline Cases (no.) & 958 \\
\hline Male & 571 \\
\hline Female & 387 \\
\hline Mean age at study encounter \pm SD (yr) & $31.2 \pm 16.7$ \\
\hline Range & $3-73$ \\
\hline Mean age at onset of $\mathrm{VL} \pm \mathrm{SD}(\mathrm{yr})$ & $26.8 \pm 15.3$ \\
\hline \multicolumn{2}{|l|}{ Religious Group (no.) } \\
\hline Hindu & 850 \\
\hline Muslim & 108 \\
\hline Controls (no.) & 1015 \\
\hline Male & 570 \\
\hline Female & 445 \\
\hline Mean age at study encounter \pm SD (yr) & $31.8 \pm 15.9$ \\
\hline \multicolumn{2}{|l|}{ Religious Group (no.) } \\
\hline Hindu & 885 \\
\hline Muslim & 130 \\
\hline
\end{tabular}

\footnotetext{
* Numbers are given for the individuals with DNA available for genotyping
} 
accompanied by demonstration of clinical response to anti-leishmanial treatment (typically with amphotericin B). An annual incidence rate of 2.49 clinical VL cases/1,000 persons has been reported in the region [20]. L. donovani sensu strictu (zymodeme MON-2) was confirmed as the causative agent of VL in the study region, in accordance with other reports on clinical isolates from kala-azar patients in the state of Bihar [21-24]. Additional epidemiological and demographic details relating to the study site are described elsewhere [25]. Informed written consent in Hindi was obtained from all participating individuals and from parents of children under 18 years old. Approval for the study was provided by the Ethical Committee of the Institute of Medical Sciences, Banaras Hindu University, Varanasi, India. Collection of families for the primary study was undertaken between 2004 and 2006. The replication study collection was undertaken during 2009-2010. For the family-based primary study DNA was prepared from buccal swabs by whole genome amplification as described [18], and SNPs genotyped using ABI predesigned Taqman assays (ABI, Mulgrave, Victoria, Australia). For the replication case-control study, genomic DNA was extracted from saliva using the Oragene technology (DNA Genotek, Ontario, Canada), and SNPs genotyped using Sequenom iPLEX platform (Sequenom, San Diego, CA). The $\mathrm{GT}_{\mathrm{n}}$ repeat and IN/DELS were genotyped for all samples using $\mathrm{ABI}$ fragment analysis processed on an ABI3130 (Australia) or ABI3730 (India) Genetic Analyser.

Family-based allelic association tests based on the TDT but generalized to allow analysis under additive and genotype-wise models of inheritance were performed within FBAT under the null hypothesis of "no linkage and no association" [26,27]. TDT power approximations [28] show that the 313 primary VL trios had $\geq 95 \%$ power to detect an odds ratio $\geq 2$ at $P=0.01$ for markers with $\mathrm{MAF} \geq 0.1$, but only $49 \%$ power for an odds ratio of 1.5. Nevertheless, our primary sample was well-powered to detect effect sizes (odds ratios $\geq 2$ ) equivalent to those observed in the earlier study of SLC11A1 and VL in Sudan [12]. Robust association tests were performed to take account of multiple trios within a pedigree. Association tests for the replication casecontrol sample were undertaken using logistic regression analysis performed in PLINK [29] or LOGIT (Stata) using an additive model and a genotypic test. The 941 cases and 992 controls which passed quality control (Hardy-Weinberg Equilibrium) had 100\% power to detect associations with an odds ratio of 2 for markers with $\mathrm{MAF} \geq 0.1$ at $P=0.001$, and $93.5 \%$ power for odds ratio 1.5 ; $\mathrm{MAF} \geq 0.1, P=0.01$.

Splenic biopsies were taken as part of routine diagnostic procedure at the Kala Azar Medical Research Centre, Muzaffarpur, Bihar State, India. Since the spleen is a major focus for parasite growth inside macrophages, this afforded an important opportunity to analyse gene expression in a primary site of infection. Pre- and posttreated patient's splenic samples were collected in $5 \times$ RNA Later (Ambion) during 2009-2010, transported to Varanasi at $4^{\circ} \mathrm{C}$ and stored at $-80^{\circ} \mathrm{C}$ until RNA was isolated. Details regarding age and sex (15 males, median age 16, range 7 to 45 years; 9 females, median age 10 , range 8 to 30 years) splenic parasites (21 confirmed positive; 3 not done) and drug administered (19 Miltefosine; 1 Miltefosine + Paramomycin; 1Ambisome + Paramomycin; 3Amphomul) were recorded for each patient. Total RNA was isolated using RNeasy tissue kit (Qiagen) according to the manufacturer's instructions and eluted in $30 \mathrm{ul}$ of RNase free water. Sample quality and integrity was assessed by ND-2000 spectrophotometer (Thermo Fischer Scientific) and agarose (Sigma Aldrich) gel electrophoresis. 500 ng of RNA was reverse transcribed using the High Capacity cDNA synthesis kit (Applied Biosystems). Taqman predesigned gene expression assay (Hs00184453_m1) was used to perform expression studies (7500 HT Real Time PCR system, ABI, Foster City CA, USA) with $18 \mathrm{~S}$ rRNA (P/N 4319413E) used as an endogenous control to normalize the expression data. Experiments were performed on 24 paired pre- and posttreatment splenic aspirates from VL patients with appropriate no RT and no template controls included in each plate. All samples were run in duplicate. Results were analysed by 7500 software v.2.0.1 and Graph pad prism 5 . Paired Student's T tests was used to test for significant differences between pre (Day-0) and post (D-30) expression levels for each genotype, i.e. $3 / 3,3 / 2$ and $2 / 2$. One way ANOVA was used to test for differences between 3/ 3 vs $3 / 2$ vs $2 / 2$ groups at either Day- 0 or Day- 30 .

\section{Results and Discussion}

To undertake our study we initially genotyped 9 polymorphisms (Table 2) in 176 nuclear families (Table 1) used in our previous study [18] that contain 313 offspring with VL collected in the area of Muzaffarpur, Bihar State, India, where L. donovani is endemic. This included the putative functional 5' $\mathrm{GT}_{\mathrm{n}}$ repeat and 3'UTR TGTG/and CAAA/ - IN/DELs, as well as the exon $3274 \mathrm{C} / \mathrm{T}$ (rs2276631) and intron $4469+14 \mathrm{G} / \mathrm{C}$ (rs3731865) SNPs shown to be associated with VL in Sudan [12]. Using the family-based association test (FBAT) $[30,31]$ in this primary family dataset (Table 3 ) we found tentative evidence (nominal $P$-values $\leq 0.05$ ) for associations between VL and 5' $\mathrm{GT}_{\mathrm{n}}$ repeat, and between VL and the 3'UTR CAAA/- IN/DEL. In particular (Table 3B), homozygosity for the high expressing pro-inflammatory allele 3 at the $\mathrm{GT}_{\mathrm{n}}$ repeat was associated with disease (Z-score = +2.382; nominal $P=0.017$ ), while homozygosity for allele 2 (the deletion) was associated with protection for the 3'UTR CAAA IN/DEL (Z-score $=-2.332$; nominal $P=$ 
Table 2 Details of polymorphisms genotyped and the minor allele frequency (MAF) of variants in the Indian study population

\begin{tabular}{|c|c|c|c|c|c|c|}
\hline Common Designation & Location & Amino Acid Change & SNP Identity & Physical Position ${ }^{1}$ (bp) & Alleles $^{2}$ & MAF \\
\hline GTn & $5^{\prime} \cup T R$ & & rs34448891 & 218954900 & $118 / 120^{4}$ & 0.190 \\
\hline$-237 C / T$ & $5^{\prime} U T R$ & & rs7573065 & 218954951 & $\mathrm{C} / \mathrm{T}$ & 0.068 \\
\hline $274 C / T^{3}$ & Exon 3 & F66F & rs2276631 & 218957257 & $\mathrm{G} / \mathrm{A}$ & 0.141 \\
\hline $469+14 \mathrm{G} / \mathrm{C}^{3}$ & Intron 4 & & rs3731865 & 218958247 & $C / G$ & 0.142 \\
\hline $823 \mathrm{C} / \mathrm{T}^{3}$ & Exon 8 & G249G & rs17221959 & 218960874 & $\mathrm{C} / \mathrm{T}$ & 0.193 \\
\hline $1465-85 G / A^{3}$ & Intron 13 & & rs2279015 & 218967514 & $\mathrm{C} / \mathrm{T}$ & 0.323 \\
\hline $\mathrm{D} 543 \mathrm{~N} G / \mathrm{A}^{3}$ & Exon 15 & D543N & rs17235409 & 218967976 & $\mathrm{G} / \mathrm{A}$ & 0.073 \\
\hline $1729+55 \mathrm{del} 4^{3}$ (TGTG) & 3'UTR & & rs17235416 & 218968058 & IN/DEL & 0.067 \\
\hline $1729+263 \mathrm{del}^{3}$ (CAAA) & $3^{\prime} U T R$ & & rs17229009 & 218968275 & DEL/IN & 0.287 \\
\hline
\end{tabular}

${ }^{1}$ Physical positions of markers are given according to Build 36.3 of the human genome; ${ }^{2}$ Major $>$ minor alleles for this Indian population; ${ }^{3}$ bp positions of variants relative to an arbitrary site $76 \mathrm{bp}$ upstream [33] of the methionine start codon; ${ }^{4}$ allele $3 /$ allele 2 (alleles 1 and 4 were rare or absent from this population).

0.019). Since these two markers are not in strong LD with each other (Additional Figure 1: D'=0.52; r2 = 0.16), these associations are likely to be independent, if real. Neither association is robust to application of a strict Bonferroni correction for 9 SNPs genotyped, which requires a significance cut-off of $P \leq 0.006$ (i.e. $P=0.05$ /
9). Given that the 8 SNPs that passed quality control are not all independent (Additional Figure 1), this is overconservative. A less stringent correction taking account of non-independence of markers provides a cut-off of $P \leq$ 0.017 (i.e. $P=0.05 / 3$; 2 LD blocks plus 1 independent marker).

Table 3 Family-based association analysis between SLC11A1 and VL

\begin{tabular}{|c|c|c|c|c|c|c|c|c|}
\hline \multicolumn{9}{|c|}{ (A) Additive model } \\
\hline Common Designation & Allele & Allele frequency & \# Fam & $S$ & $E(S)$ & $\operatorname{Var}(\mathbf{S})$ & Z & $P$ \\
\hline \multirow[t]{2}{*}{$\mathrm{GT}_{\mathrm{n}}$} & 2 & 0.15 & 68 & 60 & 70.38 & 28.4 & -1.947 & 0.052 \\
\hline & 3 & 0.85 & 68 & 176 & 165.62 & 28.4 & 1.947 & 0.052 \\
\hline \multirow[t]{2}{*}{$274 \mathrm{C} / \mathrm{T}$} & 1 & 0.88 & 43 & 104 & 99.65 & 16.3 & 1.076 & 0.282 \\
\hline & 2 & 0.12 & 43 & 36 & 40.35 & 16.3 & -1.076 & 0.282 \\
\hline \multirow[t]{2}{*}{$469+14 G / C$} & 1 & 0.11 & 20 & 17 & 21.50 & 9.7 & -1.445 & 0.148 \\
\hline & 2 & 0.89 & 20 & 61 & 56.50 & 9.7 & 1.445 & 0.148 \\
\hline \multirow[t]{2}{*}{$823 \mathrm{C} / \mathrm{T}$} & 1 & 0.92 & 46 & 127 & 121.97 & 20 & 1.127 & 0.260 \\
\hline & 2 & 0.08 & 46 & 41 & 46.03 & 20 & -1.127 & 0.260 \\
\hline \multirow[t]{2}{*}{$1465-85 \mathrm{G} / \mathrm{A}$} & 1 & 0.31 & 92 & 117 & 119.63 & 42.9 & -0.402 & 0.688 \\
\hline & 2 & 0.69 & 92 & 229 & 226.37 & 42.9 & 0.402 & 0.688 \\
\hline \multirow[t]{2}{*}{1729 + 55del4 (TGTG) } & 1 & 0.05 & 19 & 18 & 21.50 & 9.57 & -1.131 & 0.258 \\
\hline & 2 & 0.95 & 19 & 54 & 50.50 & 9.57 & 1.131 & 0.258 \\
\hline \multirow[t]{2}{*}{$1729+263$ del4 (CAAA) } & 1 & 0.74 & 88 & 216 & 203.33 & 41.2 & 1.974 & 0.048 \\
\hline & 2 & 0.26 & 88 & 104 & 116.67 & 41.2 & -1.974 & 0.048 \\
\hline \multicolumn{9}{|c|}{ (B) Genotype-wise model } \\
\hline Common Designation & Genotype & Genotype frequency & \# Fam & $S$ & $E(S)$ & $\operatorname{Var}(\mathrm{S})$ & $z$ & $P$ \\
\hline \multirow[t]{3}{*}{$\mathrm{GT}_{\mathrm{n}}$} & $2 \backslash 2$ & 0.025 & 9 & 8 & 6.69 & 2.9 & 0.759 & 0.447 \\
\hline & $2 \backslash 3$ & 0.250 & 68 & 44 & 57.00 & 25.7 & -2.565 & 0.010 \\
\hline & $3 \backslash 3$ & 0.725 & 65 & 66 & 54.31 & 24.1 & 2.382 & 0.017 \\
\hline \multirow[t]{3}{*}{$1729+263$ del4 (CAAA) } & $1 \backslash 1$ & 0.566 & 75 & 69 & 63.57 & 27.9 & 1.027 & 0.304 \\
\hline & $1 \backslash 2$ & 0.347 & 87 & 78 & 76.19 & 33.9 & 0.311 & 0.755 \\
\hline & $2 \backslash 2$ & 0.087 & 26 & 13 & 20.24 & 9.64 & -2.332 & 0.019 \\
\hline
\end{tabular}

FBAT analysis under (A) additive and (B) genotype-wise models of inheritance for associations between SLC11A1 polymorphisms and the primary family-based sample of VL from Bihar State, India. \# Fam = number of families informative for the FBAT analysis; $\mathrm{S}$ and $\mathrm{E}(\mathrm{S})$ represent the observed and expected transmissions for that allele, $\operatorname{Var}(S)$ is the variance. A positive $Z$ score indicates association with disease; a negative $Z$ score indicates the non-associated or protective allele or genotype. Bold indicates significant associations at nominal $P \leq 0.05$. The corrected $P$-value required to achieve significance taking account of multiple but not independent markers is $P \leq 0.017$. Results are shown for the 7 polymorphisms that were genotyped in the primary family-based sample. All passed HWE ( $P$-value cut-off $0.05 / 7=0.07$ for 7 markers genotyped) in unaffected family founders. 


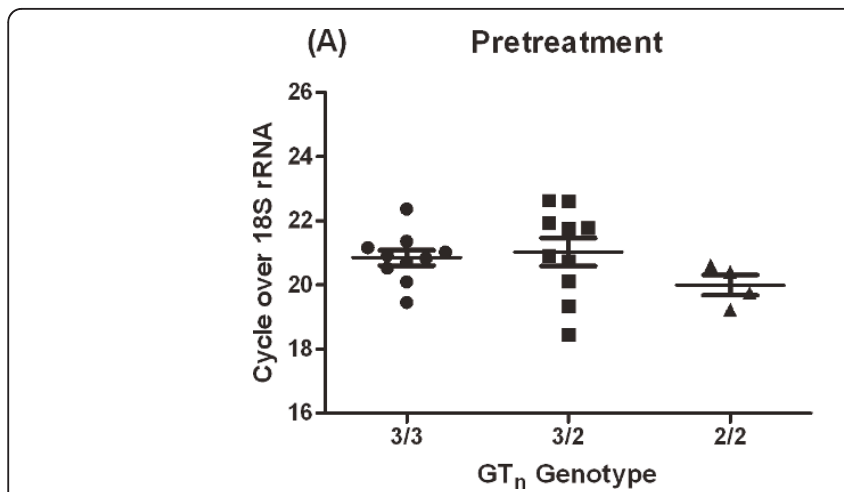

(B) Post treatment

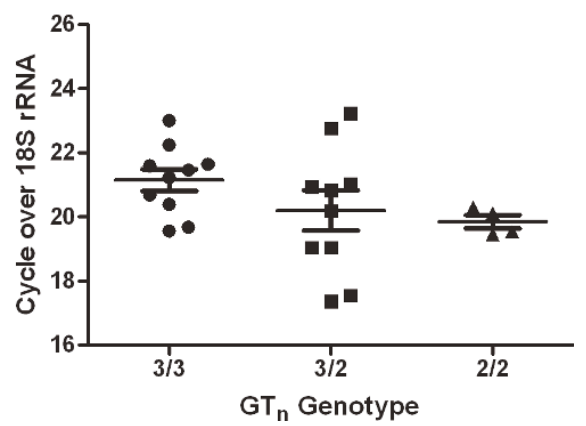

Figure 1 Relative expression of SLC11A1 mRNA in splenic aspirates from VL patients (A) before (Day 0), and (B) after (Day 30), antileishmanial treatment. Data are shown according to genotype $(3 / 3,2 / 3,2 / 2)$ at the SLC11A1 GT promoter repeat polymorphism. Values represent mean \pm SEM. Paired Student's T test showed no significant differences in expression of SLC11A1 when D0 values were compared to D30 valules for each genotype. No differences between genotypes were observed at either D0 or D30 as deteremined by one way ANOVA.

Suggestive evidence for an association between Indian $\mathrm{VL}$ and allele 3 at the functional promoter region $\mathrm{GT}_{\mathrm{n}}$ polymorphism at SLC11A1, which was consistent with data for VL from Sudan [12], prompted us to pursue two further avenues of investigation. First, we looked at expression levels of SLC11A1 in mRNA from splenic aspirates from patients carrying the 3 different genotypes at the $\mathrm{GT}_{\mathrm{n}}$ repeat (Figure 1). This failed to show any significant differences in expression levels of SLC11A1 in splenic aspirates from VL patients carrying the three $\mathrm{GT}_{\mathrm{n}}$ genotypes, either before or after treatment, as determined using one way ANOVA. Nor were there differences in expression within each genotype when pre- and post-treatment values were compared using paired Student's T tests. This suggests that differences in expression levels driven by the $\mathrm{GT}_{\mathrm{n}}$ repeat in luciferase assays in vitro, especially under lipopolysaccharide and interferon $-\gamma$ stimulation $[13,32]$, do not necessarily translate into regulation of expression in VL infected spleens in vivo. Secondly, we carried out a comprehensive replication of the association study in a much larger population-based case-control sample from the same region of Bihar State in India (Table 4).

Table 4 Population-based association analysis between SLC11A1 and VL

\begin{tabular}{|c|c|c|c|c|c|c|c|}
\hline \multicolumn{8}{|c|}{ (A) Logistic regression test under additive model } \\
\hline Common Designation & Allele & Affected & Unaffected & OR & L95 & U95 & $P$ \\
\hline $\mathrm{GT}_{\mathrm{n}}$ & 2 & $355 / 1473$ & $353 / 1533$ & 1.05 & 0.89 & 1.23 & 0.585 \\
\hline$-237 \mathrm{C} / \mathrm{T}$ & 2 & $135 / 1747$ & $122 / 1862$ & 1.18 & 0.91 & 1.52 & 0.205 \\
\hline $274 C / T$ & 2 & $258 / 1624$ & $286 / 1698$ & 1.06 & 0.88 & 1.27 & 0.529 \\
\hline $469+14 G / C$ & 1 & $266 / 1582$ & $274 / 1632$ & 1.00 & 0.83 & 1.19 & 0.987 \\
\hline $1465-85 \mathrm{G} / \mathrm{A}$ & 1 & $605 / 1263$ & $646 / 1308$ & 1.03 & 0.90 & 1.18 & 0.664 \\
\hline D543N G/A & 2 & $145 / 1735$ & $112 / 1526$ & 0.88 & 0.68 & 1.14 & 0.313 \\
\hline $1729+55$ del4 (TGTG) & 1 & $110 / 1488$ & $112 / 1608$ & 1.06 & 0.81 & 1.39 & 0.669 \\
\hline $1729+$ 263del4 (CAAA) & 2 & $437 / 1123$ & $515 / 1233$ & 0.93 & 0.80 & 1.08 & 0.364 \\
\hline \multicolumn{8}{|c|}{ (B) Genotypic-wise logistic regression analysis (2df) } \\
\hline Common Designation & Genotypes & Cases & Controls & OR & $P$ & & \\
\hline \multirow[t]{3}{*}{$G T_{n}$} & $2 / 2$ & 40 & 27 & 1 & - & & \\
\hline & $2 / 3$ & 275 & 299 & 0.62 & 0.070 & & \\
\hline & $3 / 3$ & 599 & 617 & 0.66 & 0.098 & & \\
\hline \multirow[t]{3}{*}{$1729+263$ del4 (CAAA) } & $2 / 2$ & 67 & 79 & 1 & - & & \\
\hline & $1 / 2$ & 303 & 357 & 0.91 & 0.346 & & \\
\hline & $1 / 1$ & 410 & 438 & 0.90 & 0.583 & & \\
\hline
\end{tabular}

Logistic regression analyses under (A) an additive model and (B) using a genotypic ( $2 \mathrm{df}$ ) test for the replication sample of VL cases and controls from Bihar State, India OR = odds ratio (for minor allele relative to major allele in part A); L95 and U95 are lower and upper $95 \%$ confidence intervals. In (A) allele counts are shown for mino/major allele for affected and unaffected individuals. There were no significant associations at nominal $P \leq 0.05$. The corrected $P$-value required to achieve significance taking account of multiple but not independent markers is $P \leq 0.017$. Data are shown for all markers that were in HWE ( $P$-value cut-off $0.05 /$ $9=0.006$ for 9 markers genotyped) in the control sample. Marker $823 \mathrm{C} / \mathrm{T}$ failed HWE quality control. Markers D543N G/A (0.1\% cases versus $17 \%$ controls) and $1729+263$ del 4 (CAAA) (17\% cases versus $10.7 \%$ controls) showed differential missingness between cases and controls, which can be a concern for its potential to generate false positive results [34]. 
This study failed to show association between VL and any of the 8 markers that passed quality control. The trend for genotypic association at the $\mathrm{GT}_{\mathrm{n}}$ was in the reverse direction (i.e. a3 was the risk allele in the primary sample, and the protective allele in the replication samples) to that seen in the primary analysis (Table 3). Analyses using caste, which we have shown to provide a good surrogate for population substructure in genome-wide analyses (unpublished data), or religion as covariates also failed to provide evidence for positive associations in the case-control analysis (data not shown).

Here we re-examined $S L C 11 A 1$ as a candidate gene for susceptibility to VL in India. Despite preliminary evidence for a role for putative functional polymorphisms in the 5 ' promoter and 3'UTR regions, we were unable to find supporting evidence for this in functional studies or in a large, well-powered, replication sample for association analysis. We conclude that $S L C 11 A 1$ does not play a major role in determining susceptibility to $\mathrm{VL}$ in India. These results also call into question the earlier association observed between VL and SLC11A1 in Sudan [12], which was based on a single small sample of families. Whilst this could represent genetic heterogeneity between human populations and/or the parasite, it is also possible that this first report of association in humans could be a case of beginner's curse. Results presented here suggest that associations observed in small-scale primary samples require validation to determine whether they remain true for the population in which they have been observed.

\section{Conclusions}

This is the first well-powered study of SLC11A1 as a candidate for $\mathrm{VL}$, which we conclude does have a major role in regulating VL susceptibility in India.

\section{Additional material}

Additional File 1: Figure S1. Haploview analysis for $\mathrm{D}^{\prime}$ and $\mathrm{r}^{2}$ pairwise measures of linkage disequilibrium between SLC11A1 polymorphisms in the control sample for the replication sample from India.

\footnotetext{
Acknowledgements

We would like to thank the families from the state of Bihar, northeast India for their participation in this study. The authors declare no conflict of interest. This research was funded by grants from The Wellcome Trust in the UK (grant numbers: 074196/Z/04/Z and 085475/Z/08/Z) and The National Institutes for Health in the USA (grant numbers: R01 Al076233-01 and 1P50Al074321-01).

Author details

'Institute of Medical Sciences, Banaras Hindu University, Varanasi, OS 221 005, India. ${ }^{2}$ Telethon Institute for Child Health Research, Centre for Child Health Research, The University of Western Australia, Subiaco, Western Australia, Australia. ${ }^{3}$ Cambridge Institute for Medical Research and Department of Medicine, University of Cambridge School of Clinical
}

Medicine, Cambridge, UK. ${ }^{4}$ Centre for Cellular and Molecular Biology, Hyderabad, India.

\section{Authors' contributions}

AM, MF and SM carried out the field collection and/or preparation of the samples. SM and JO performed the genotyping, and participated in the statistical analysis and interpretation of the data. SEJ trained SM in the laboratory for genotyping techniques, in database entry and use of the genetic database GenIE in Perth, and in genetic statistical analysis methods. MF cross-checked statistical analyses and carried out additional statistical tests. MR oversaw laboratory-based work in Varanasi. DSR and KT oversaw the Sequenom genotyping undertaken by SM in Hyderabad. MS and PT assisted with RNA preparation. SM designed and carried out the QRT/PCR. SS helped conceive the study, was responsible for clinical care of cases at the Kala Azar Medical Research Centre, Muzaffarpur, Bihar State, India, and provided the logistical support to make the study possible. SM prepared the first draft of the manuscript. JMB designed the study, conceived the specific hypothesis to be tested, made the final interpretation of the data, and prepared the final manuscript. All authors read and approved the final manuscript.

\section{Competing interests}

The authors declare that they have no competing interests.

Received: 22 February 2011 Accepted: 20 May 2011

Published: 20 May 2011

\section{References}

1. Desjeux P: The increase in risk factors for leishmaniasis worldwide. Trans R Soc Trop Med Hyg 2001, 95(3):239-243.

2. Badaro R, Jones TC, Lorenco R, Cerf BJ, Sampaio D, Carvalho EM, Rocha H, Teixeira R, Johnson WD Jr: A prospective study of visceral leishmaniasis in an endemic area of Brazil. J Infect Dis 1986, 154(4):639-649.

3. Peacock CS, Collins A, Shaw MA, Silveira F, Costa J, Coste CH, Nascimento MD, Siddiqui R, Shaw JJ, Blackwell JM: Genetic epidemiology of visceral leishmaniasis in northeastern Brazil. Genet Epidemiol 2001, 20(3):383-396.

4. Cabello PH, Lima AM, Azevedo ES, Krieger H: Familial aggregation of Leishmania chagasi infection in northeastern Brazil. Am J Trop Med Hyg 1995, 52(4):364-365.

5. Zijlstra EE, el-Hassan AM, Ismael A, Ghalib HW: Endemic kala-azar in eastern Sudan: a longitudinal study on the incidence of clinical and subclinical infection and post-kala-azar dermal leishmaniasis. Am J Trop Med Hyg 1994, 51(6):826-836.

6. Blackwell JM, Mohamed HS, Ibrahim ME: Genetics and visceral leishmaniasis in the Sudan: seeking a link. Trends Parasitol 2004, 20(6):268-274.

7. Blackwell JM, Fakiola M, Ibrahim ME, Jamieson SE, Jeronimo SB, Miller EN, Mishra A, Mohamed HS, Peacock CS, Raju M, Sundar S, Wilson ME: Genetics and visceral leishmaniasis: of mice and man. Parasite Immunol 2009, 31(5):254-266.

8. Blackwell JM, Goswami T, Evans CAW, Sibthorpe D, Papo N, White JK, Searle S, Miller EN, Peacock CS, Mohammed H, Ibrahim M: SLC11A1 (formerly NRAMP1) and disease. Cell Microbiol 2001, 3:773-784.

9. Blackwell JM, Searle S, Mohamed H, White JK: Divalent cation transport and susceptibility to infectious and autoimmune disease: continuation of the Ity/Lsh/Bcg/Nramp1/Slc11a1 gene story. Immunol Lett 2003, 85(2):197-203.

10. Vidal SM, Malo D, Vogan K, Skamene E, Gros P: Natural resistance to infection with intracellular parasites: isolation of a candidate for Bcg. Cell 1993, 73:469-485.

11. Goswami T, Bhattacharjee A, Babal P, Searle S, Moore E, Li M, Blackwell JM: Natural-resistance-associated macrophage protein 1 is an $\mathrm{H}+$ /bivalent cation antiporter. Biochem J 2001, 354(Pt 3):511-519.

12. Mohamed HS, Ibrahim ME, Miller EN, White JK, Cordell HJ, Howson JMM, Peacock CS, Khalil EAG, Elhassan AM, Blackwell JM: SLC11A1 (formerly NRAMP1) and susceptibility to visceral leishmaniasis in The Sudan. Eur f Hum Genet 2004, 12:66-74.

13. Searle S, Blackwell JM: Evidence for a functional repeat polymorphism in the promoter of the human NRAMP1 gene that correlates with 
autoimmune versus infectious disease susceptibility. J Med Genet 1999, 36(4):295-299.

14. Blackwell JM, Jiang HR, White JK: Role of Nramp family in proinflammatory diseases. In The Nramp Family. Edited by: Cellier MFM, Gros P. Kluwer Academic/Landes, New York, NY; 2004:53-64.

15. Awomoyi AA, Marchant A, Howson JM, McAdam KP, Blackwell JM, Newport MJ: Interleukin-10, polymorphism in SLC11A1 (formerly NRAMP1), and susceptibility to tuberculosis. J Infect Dis 2002, 186:1804-1814.

16. Barral-Netto M, Badaro R, Barral A, Almeida RP, Santos SB, Badaro F, PedralSampaio D, Carvalho EM, Falcoff E, Falcoff R: Tumor necrosis factor (cachectin) in human visceral leishmaniasis. J Infect Dis 1991, 163:853-857.

17. Burgner D, Jamieson SE, Blackwell JM: Genetic susceptibility to infectious diseases: big is beautiful, but will bigger be even better? Lancet Infect Dis 2006, 6(10):653-663.

18. Fakiola M, Mishra A, Rai M, Singh SP, O'Leary RA, Ball S, Francis RW, Firth MJ, Radford BT, Miller EN, Sundar S, Blackwell JM: Classification and regression tree and spatial analyses reveal geographic heterogeneity in genome wide linkage study of Indian visceral leishmaniasis. PLOS ONE 2010, 5(12): e15807.

19. Sundar S, Benjamin B: Diagnosis and treatment of Indian visceral sleishmaniasis. J Assoc Physicians India 2003, 51:195-201.

20. Singh SP, Reddy DC, Rai M, Sundar S: Serious underreporting of visceral leishmaniasis through passive case reporting in Bihar, India. Trop Med Int Health 2006, 11(6):899-905.

21. Manna M, Majumder HK, Sundar S, Bhaduri AN: The molecular characterization of clinical isolates from Indian Kala-azar patients by MLEE and RAPD-PCR. Med Sci Monit 2005, 11(7):BR220-227.

22. Sundar S, Pai K, Kumar R, Pathak-Tripathi K, Gam AA, Ray M, Kenney RT: Resistance to treatment in Kala-azar: speciation of isolates from northeast India. Am J Trop Med Hyg 2001, 65(3):193-196.

23. Thakur CP, Dedet JP, Narain S, Pratlong F: Leishmania species, drug unresponsiveness and visceral leishmaniasis in Bihar, India. Trans $R$ Soc Trop Med Hyg 2001, 95(2):187-189.

24. Chatterjee M, Manna M, Bhaduri AN, Sarkar D: Recent kala-azar cases in India: isozyme profiles of Leishmania parasites. Indian J Med Res 1995, 102:165-172.

25. Singh SP, Reddy DC, Mishra RN, Sundar S: Knowledge, attitude, and practices related to Kala-azar in a rural area of Bihar state, India. Am J Trop Med Hyg 2006, 75(3):505-508.

26. Laird NM, Horvath S, Xu X: Implementing a unified approach to familybased tests of association. Genet Epidemiol 2000, 19(Suppl 1):S36-42.

27. Horvath $S, X u X$, Laird NM: The family based association test method: strategies for studying general genotype-phenotype associations. Eur $J$ Hum Genet 2001, 9(4):301-306.

28. Knapp M: A note on power approximations for the transmission disequilibrium test. Am J Hum Genet 1999, 64(4):1177-1185.

29. Purcell $S$, Neale B, Todd-Brown K, Thomas L, Ferreira MA, Bender D, Maller J, Sklar P, de Bakker PI, Daly MJ, Sham PC: PLINK: a tool set for wholegenome association and population-based linkage analyses. Am J Hum Genet 2007, 81(3):559-575.

30. Laird NM, Horvath $S, X u X$ : Implementing a unified approach to familybased tests of association. Genet Epidemiol 2000, 19(Suppl 1):S36-42.

31. Horvath $S, X U X$, Laird NM: The family based association test method: strategies for studying general genotype-phenotype associations. Eur J Hum Genet 2001, 9(4):301-306.

32. Zaahl MG, Robson KJ, Warnich L, Kotze MJ: Expression of the SLC11A1 (NRAMP1) $5^{\prime}-(\mathrm{GT}) \mathrm{n}$ repeat: opposite effect in the presence of $-237 \mathrm{C}->\mathrm{T}$. Blood Cells Mol Dis 2004, 33(1):45-50.

33. Liu J, Fujiwara TM, Buu NT, Sanchez FO, Cellier M, Paradis AJ, Frappier D, Skamene E, Gros P, Morgan K, Schurr E: Identification of polymorphisms and sequence variants in human homologue of the mouse natural resistance-associated macrophage protein gene. Am J Hum Genet 1995, 56:845-853.

34. Clayton DG, Walker NM, Smyth DJ, Pask R, Cooper JD, Maier LM, Smink L, Lam AC, Ovington NR, Stevens HE, Nutland S, Howson JM, Faham M, Moorhead M, Jones HB, Falkowski M, Hardenbol P, Willis TD, Todd JA: Population structure, differential bias and genomic control in a largescale, case-control association study. Nat Genet 2005, 37(11):1243-1246.

\section{Pre-publication history}

The pre-publication history for this paper can be accessed here: http://www.biomedcentral.com/1471-2350/12/71/prepub

doi:10.1186/1471-2350-12-71

Cite this article as: Mehrotra et al:: No evidence for association between SLC11A1 and visceral leishmaniasis in India. BMC Medical Genetics 2011 $12: 71$.

\section{Submit your next manuscript to BioMed Central and take full advantage of:}

- Convenient online submission

- Thorough peer review

- No space constraints or color figure charges

- Immediate publication on acceptance

- Inclusion in PubMed, CAS, Scopus and Google Scholar

- Research which is freely available for redistribution 